\title{
Comparison of eleven commonly used formulae for sonographic estimation of fetal weight in prediction of actual birth weight
}

\author{
Magdalena Plonka $\odot$, Marta Bociaga $\odot$, Malgorzata Radon-Pokracka $\odot$, \\ Magdalena Nowak마, Hubert Huras@ \\ Jagiellonian Univeristy Collegium Medicum, Department of Obstertics and Perinatology, Cracow, Poland
}

\begin{abstract}
Objectives: The aim of the study is to compare the accuracy of 11 formulas in predicting fetal weight.

Material and methods: The study includes 1072 pregnant women of gestational age from 28 to 42 weeks, who gave birth between January and June 2017. Pregnant women were divided into five groups; group 1, where actual birth weight (ABW) was less than $2500 \mathrm{~g}$, group 2, where ABW was between 2500-4000 g, group 3, where ABW was above $4000 \mathrm{~g}$. Group 4 - newborns with birth weight under 10 percentile and group 5 - newborns with birth weight above 90 percentile. The accuracy of the estimated fetal weight (EFW) was assessed by calculating absolute percentage error (APE) and 'limits-of-agreement'. R Spearman correlation was utilized between EFW and ABW.

Results: The most accurate formula for group 1 is Hadlock3 (MAPE $=7.04 \%$ ), the narrowest limits of agreement has Combs — [mean (SD): $99.41 \mathrm{~g}(269.57 \mathrm{~g})$ ]. For group 2, the lowest MAPE (5.43\%) has Ott, the narrowest limits of agreement belongs to Combs - [mean (SD): $-101.36 \mathrm{~g}(275.88 \mathrm{~g})$ ] . For group 3 is Hadlock3 (MAPE $=5.79 \%)$, the narrowest limits of agreement has Hadlock5 [mean (SD): -637.32 g (209.59 g)]. For group 4 is Combs (MAPE $=7.72 \%$ ), the narrowest limits of agreement has Combs [mean (SD): $195.77 \mathrm{~g}(264.97 \mathrm{~g})$ ]. For gr oup 5 is Warsof2 (MAPE $=7.06 \%$ ), the narrowest limits of agreement has Campbell [mean (SD): $227.81 \mathrm{~g}(299.26 \mathrm{~g})$ ].
\end{abstract}

Conclusions: Median of absolute percentage error is the most useful parameter to predict birth weight. Each group of fetuses needs different formula to predict the most accurate weight.

Key words: fetal ultrasonography; estimation of fetal weight; Hadlock, SGA; LGA

Ginekologia Polska 2020; 91, 1:17-23

\section{INTRODUCTION}

Sonographic estimation of fetal weight plays an important role in obstetrics. Meaning of sonograms performed for the purpose of predicting fetal weight is rising from 24 weeks of gestation, the age of viability. Estimated fetal weight (EFW) is an essential parameter which may be helpful in decision-making during perinatal period and it can be calculated using various mathematical methods. There are several mathematical formulas that use different fetal structures to estimate fetal weight such as biparietal diameter (BPD), head circumference (HC), abdominal circumference $(A C)$, and/or femur length ( $F L)$. The accuracy of these formulas may vary, nevertheless low values have an impact on physicians' decisions. The performance of formulas may also be different in macrosomic fetuses or low-birth-weight fetuses. Macrosomia refers to growth beyond a specific threshold, regardless of gestational age. Depending on the guidelines, various thresholds are accepted, the most commonly used threshold is weight above $4500 \mathrm{~g}$. Also, weight above $4000 \mathrm{~g}$ is accepted as macrosomia. Knowledge about estimated fetal weight is useful at term for decision-making regarding mode of delivery. To identify the preterm macrosomic fetus, weight charts are used, it is established that any fetus weighing above $90^{\text {th }}$ percentile for gestational age is defined as large for gestational age. The most common serious concern connected with fetal macrosomia is shoulder dystocia, which leads to birth trauma, brachial plexus injury, clavicular fracture or asphyxia [1, 2]. 


\begin{tabular}{|c|c|c|}
\hline First author & Components & Formula \\
\hline Hadlock1 [6] & $\mathrm{HC}, \mathrm{AC}, \mathrm{FL}$ & $\log _{10} B W=1.326-0.00326(\mathrm{AC})(\mathrm{FL})+0.0107(\mathrm{HC})+0.0438(\mathrm{AC})+0.158(\mathrm{FL})$ \\
\hline Hadlock2 [6] & $\mathrm{AC}, \mathrm{FL}$ & $\log _{10} B W=1.304+0.05281(\mathrm{AC})+0.1938(\mathrm{FL})-0.004(\mathrm{AC})(\mathrm{FL})$ \\
\hline Hadlock3 [6] & $\mathrm{HC}, \mathrm{BPD}, \mathrm{AC}$ & $\log _{10} B W=1.335-0.0034(\mathrm{AC})(\mathrm{FL})+0.0316(\mathrm{BPD})+0.0457(\mathrm{AC})+0.1623(\mathrm{FL})$ \\
\hline Hadlock4 [7] & $\mathrm{HC}, \mathrm{BPD}, \mathrm{AC}, \mathrm{FL}$ & $\log _{10} B W=0.3596+0.00061(\mathrm{BPD})(\mathrm{AC})+0.0424(\mathrm{AC})+0.174(\mathrm{FL})+0.0064(\mathrm{HC})-0.00386(\mathrm{AC})(\mathrm{FL})$ \\
\hline Hadlock5 [8] & $\mathrm{HC}, \mathrm{AC}, \mathrm{FL}$ & $\log _{10} B W=1.3596+0.006(\mathrm{HC})+0.0424(\mathrm{AC})(\mathrm{FL})$ \\
\hline Shepard [9] & $B P D, A C$ & $\log _{10} B W=-1.7492+0.166(B P D)+0.046(A C)-0.002546(A C)(B P D)$ \\
\hline Campbell [10] & $\mathrm{AC}$ & $\operatorname{LnBW}=-4.564+0.0282(\mathrm{AC})-0.00331(\mathrm{AC})^{2}$ \\
\hline Warsof1 [11] & $\mathrm{FL}$ & $\operatorname{LnBW}=4.6914+0.00151(\mathrm{FL})^{2}-0.0000119(\mathrm{FL})^{3}$ \\
\hline Warsof2 [11] & $\mathrm{AC}, \mathrm{FL}$ & $\operatorname{LnBW}=2.792+0.108(\mathrm{FL})+0.0036(\mathrm{AC})^{2}-0.0027(\mathrm{FL})(\mathrm{AC})$ \\
\hline Combs [12] & $\mathrm{HC}, \mathrm{AC}, \mathrm{FL}$ & $\mathrm{BW}=0.23718(\mathrm{AC})^{2}(\mathrm{FL})+0.03312(\mathrm{HC})^{3}$ \\
\hline Ott [13] & $\mathrm{HC}, \mathrm{AC}, \mathrm{FL}$ & $\log _{10} B W=-2.0661+0.04355(\mathrm{HC})+0.05394(\mathrm{AC})-0.0008582(\mathrm{HC})(\mathrm{AC})+1.2594(\mathrm{FL} / \mathrm{AC})$ \\
\hline
\end{tabular}

$\mathrm{BPD}$ - biparietal diameter; $\mathrm{HC}$ - head circumference; $\mathrm{AC}$ - abdominal circumference; $\mathrm{FL}$ - femur length; BW — birth weight

Low birth weight is defined as less than $2500 \mathrm{~g}$ at the first weight determination after birth, it is associated with fetal prematurity or small for gestational age. Small for gestational age (SGA) is defined as infants with a body weight below the $10^{\text {th }}$ percentile for gestational age and comprises infants who are constitutionally normally small and those who are small because of fetal restriction [3]. Infants with fetal of growth restriction are at increased risk for morbidity and mortality [4]. Any stage requires medical intervention, proper time and mode of delivery. Nowadays, estimation fetal weight could be also improved by using three-dimensional ultrasound [5]. The aim of the study was to compare the accuracy of 11 formulas in predicting fetal weight, which are the most widespread between gynecologists.

\section{MATERIAL AND METHODS}

The retrospective cohort study included 1072 pregnant women of gestational age from 28 to 42 weeks, who gave birth in Department of Obstetrics and Perinatology JU MC between January and June 2017. The inclusion criteria were: Caucasian, race, singleton pregnancies and the interval between estimation of fetal weight and delivery within 48 hours. Intrauterine fetal deaths and fetuses with lethal defects were excluded. We divided pregnant women into five groups depending on actual birth weight (ABW); group 1 comprising 40 patients,where actual birth weight (ABW) was less than $2500 \mathrm{~g}$, group 2 including 932 patients, where ABW was between 2500-4000 g, group 3 with 100 patients, where ABW was above $4000 \mathrm{~g}$. According to ABW, we have analyzed weight charts. Group 4 includes newborns with birth weight under 10 percentile and group 5 - newborns with birth weight above 90 percentile. UItrasound examinations were performed by obstetricians who underwent the same training course, with the use of General Electric Voluson ultrasound device with 4-8 $\mathrm{MHz}$ transabdominal curvilinear transducer. In cases which the ultrasound examination was repeated, only the last examination before delivery was taken into account. Each fetus was included only once. Birth weight and neonatal weight were obtained within $1 \mathrm{~h}$ after delivery by the nursing staff. We evaluated 11 widely accepted weight formulas (Tab. 1). Measurement were performed by doctors as a part of diagnostic work-up before delivery, informed consent was obtained from all individuals on admission included in these study. The study was approved by Bioethics Committee of the University.

\section{Statistical analysis}

Data were analyzed using STATISTICA 13.1 statistical analysis software. The accuracy of the EFW was assessed by calculating absolute percentage error (APE): |(EFW - ABW)/ /ABW| $\times 100 \%$ in order to predict accuracy of a formula. Differences between the weight formulas were compared using Wilcoxon's test for median absolute percentage error (MAPE) values at a significance level $<0.05$. We chose median due to nonparametric distribution of data.We compared the lowest MAPE and and the other equations. We utilized R Spearman correlation to evaluate the power of relationship between actual birth weight and estimated fetal weight. Accuracy was also determined with the 'limits-of-agreement' method described by Bland and Altman [14]. The overall median difference between fetal weight and birth weight is connected with the systematic error, while the limits of agreement refer to the random error. The $95 \%$ limits of agreement show the difference between the birth weight and the EFW that can be expected, and which tendency (to underestimate or overestimate) is found. 


\begin{tabular}{|c|c|c|c|c|c|}
\hline & $\begin{array}{l}\text { Group } 1 \\
(\leq 2500)\end{array}$ & $\begin{array}{l}\text { Group } 2 \\
(2500-4000)\end{array}$ & $\begin{array}{l}\text { Group } 3 \\
(\geq 4000)\end{array}$ & $\begin{array}{l}\text { Group } 4 \\
\text { (<10 cent.) }\end{array}$ & $\begin{array}{l}\text { Group } 5 \\
(>90 \text { cent.) }\end{array}$ \\
\hline Sample size & 40 & 932 & 100 & 94 & 123 \\
\hline Maternal age, years, mean (SD) & $31.81(5.64)$ & $31.69(4.66)$ & $31.34(3.88)$ & $32.36(4.89)$ & $31.70(4.66)$ \\
\hline $\begin{array}{l}\text { Mean gestational age the time of ultrasound examination, } \\
\text { weeks, median (range) }\end{array}$ & $\begin{array}{l}34.36 \\
(28.00-41.29)\end{array}$ & $\begin{array}{l}39.14 \\
(33.43-42.00)\end{array}$ & $\begin{array}{l}40.00 \\
(36.57-41.14)\end{array}$ & $\begin{array}{l}39.00 \\
(30.57-42.00)\end{array}$ & $\begin{array}{l}38.86 \\
(28.00-41.00)\end{array}$ \\
\hline Parity, median (range) & $0(0-3)$ & $1(0-8)$ & $1(0-2)$ & $0(0-4)$ & $1(0-3)$ \\
\hline Maternal BMI before pregnancy, median (range) & $\begin{array}{l}22.76 \\
(17.21-38.53)\end{array}$ & $\begin{array}{l}21.77 \\
(14.37-42.24)\end{array}$ & $\begin{array}{l}23.05 \\
(18.78-55.10)\end{array}$ & $\begin{array}{l}21.09 \\
(14.86-34.77)\end{array}$ & $\begin{array}{l}22.50 \\
(18.17-55.10)\end{array}$ \\
\hline
\end{tabular}

\begin{tabular}{|c|c|c|c|c|}
\hline Regression formula & Median APE [\%] (range) & p value & mean $[g](S D)$ & $95 \%$ limits of agreement [g] \\
\hline Hadlock1 & $56.98(34.32-182.27)$ & $<0.05$ & $1262.85(287.46)$ & 699.44 to 1826.27 \\
\hline Hadlock2 & $9.54(0.67-42.10)$ & $>0.05$ & $50.72(301.48)$ & -540.19 to 641.62 \\
\hline Hadlock3 & $7.04(0.20-45.32)$ & - & $70.47(298.17)$ & -513.95 to 654.89 \\
\hline Hadlock4 & $8.08(0.21-40.77)$ & $>0.05$ & $45.21(298.44)$ & -539.73 to 630.14 \\
\hline Hadlock5 & $56.59(34.00-182.13)$ & $<0.05$ & $1256.29(288.48)$ & 690.86 to 1821.72 \\
\hline Shepard & $12.30(0.90-57.80)$ & $<0.05$ & $224.76(362.47)$ & -485.68 to 935.20 \\
\hline Campbell & $10.82(0.13-48.21)$ & $>0.05$ & $127.36(302.65)$ & -465.83 to 720.55 \\
\hline Warsof1 & $15.82(0.07-74.04)$ & $<0.05$ & $276.91(460.94)$ & -626.53 to 1180.35 \\
\hline Warsof2 & $11.51(0.34-58.12)$ & $<0.05$ & $197.64(366.84)$ & -521.38 to 916.65 \\
\hline Combs & $7.93(0.48-35.83)$ & $>0.05$ & $99.41(269.57)$ & -428.94 to 627.76 \\
\hline Ott & $8.32(0.54-40.36)$ & $>0.05$ & $101.36(287.22)$ & -461.59 to 664.31 \\
\hline
\end{tabular}

\section{RESULTS}

We identified 1072 singleton pregnancies fulfilling the inclusion criteria and divided them into five groups. Each group was separately analyzed in order to find the most accurate formula and show a tendency to underestimate or overestimate. Maternal characteristics of each study group is presented in Table 2.

Group 1 comprises 40 fetuses with ABW under $2500 \mathrm{~g}$, median of weight is $2100 \mathrm{~g}$. Table 3 shows the APE as median values (range). The lowest MAPE is found for the formula Hadlock3 (7.04\%). There is a significant difference between it and the other equations $(p<0.05)$, except from the Hadlock2, Hadlock4, Campbell, Combs and Ott ( $p>0.05$ ) formulas. Hadlock3 has also the highest value of Spearman corrrelation $(R=0.845)$. Following the strongest correlations belong to Hadlock4 ( $R=0.841)$ and Ott $(R=0.838)$. Table 3 shows agreement between estimated fetal weight and true birth weight as assessed by limits-of-agreement method. All tested formulas have a tendency to overestimate fetal weight. The narrowest limits of agreement has the EFW calculated with Combs formula. In contrast, the widest range is found for Warsof 1 formula.
Group 2 comprises 932 fetuses with ABW between $2500 \mathrm{~g}$ and $4000 \mathrm{~g}$, median of weight is $3350 \mathrm{~g}$. The lowest MAPE is found for the formula Ott $(5.43 \%)$. It differs significantly from the other equations $(p<0.05)$, only the Hadlock4, Campbell and Combs formulas are the exceptions ( $p>0.05$ ) (Tab. 4). The highest Spearman correlation are for Hadlock4 $(R=0.686)$, Hadlock1 $(R=0.683)$ and Hadlock5 $(R=0.682)$. According to Table 4, all tested formulas, except for Ott, Campbell and Combs tendency to overestimate fetal weight. The narrowest limits of agreement has Combs while the widest range has Warsof1.

Group 3 comprises 100 fetuses with ABW over $4000 \mathrm{~g}$, median of weight is $4165 \mathrm{~g}$. The lowest MAPE has Hadlock3 (5.79\%). P value below 0.05 in case of other equations, except from Hadlock2, Shepard and Warsof2, indicates there is significant difference between them and Hadlock3 formula. (Tab. 5). Spearman correlation values are the highest for Hadlock1 ( $R=0.332)$, Hadlock5 $(R=0.329)$ and Ott $(\mathrm{R}=0,328)$. Table 5 presents that all formulas have a tendency to underestimate fetal weight. The narrowest limits of agreement has Hadlock5, the widest limits of agreement belongs to Shepard. 
Table 4. The median absolute percentage error (MAPE) (left side) and limits of agreement (right side) between estimated fetal weight (g) and actual birth weight (g) for each regression formula in group 2

\begin{tabular}{|c|c|c|c|c|}
\hline Regression formula & Median APE [\%] (range) & $p$ value & mean $[g]$ (SD) & $95 \%$ limits of agreement [g] \\
\hline Hadlock1 & $7.25(0.01-40.72)$ & $<0.05$ & $179.17(318.06)$ & -444.24 to 802.57 \\
\hline Hadlock2 & $5.96(0.03-57.83)$ & $<0.05$ & $51.05(301.12)$ & -539.14 to 641.24 \\
\hline Hadlock3 & $5.73(0.02-51.25)$ & $<0.05$ & $49.63(294.87)$ & -528.31 to 627.58 \\
\hline Hadlock4 & $5.53(0.00-50.41)$ & $>0.05$ & $3.18(286.33)$ & -559.03 to 563.39 \\
\hline Hadlock5 & $7.26(0.00-40.38)$ & $<0.05$ & $171.95(317.96)$ & -451.25 to 795.15 \\
\hline Shepard & $8.91(0.03-64.97)$ & $<0.05$ & $248.77(376.25)$ & -488.68 to 986.22 \\
\hline Campbell & $5.51(0.01-48.27)$ & $>0.05$ & $-36.95(283.09)$ & -591.81 to 517.91 \\
\hline Warsof1 & $7.14(0.02-46.74)$ & $<0.05$ & $48.47(385.96)$ & -708.02 to 804.96 \\
\hline Warsof2 & $7.38(0.01-65.89)$ & $<0.05$ & $180.52(313.78)$ & -434.48 to 795.53 \\
\hline Combs & $5.56(0.01-45.91)$ & $>0.05$ & $-101.36(275.88)$ & -642.08 to 439.37 \\
\hline Ott & $5.43(0.01-51.25)$ & - & $-33.84(282.51)$ & -587.56 to 519.87 \\
\hline
\end{tabular}

\begin{tabular}{|c|c|c|c|c|}
\hline Regression formula & Median APE [\%] (range) & $p$ value & mean [g] (SD) & $95 \%$ limits of agreement [g] \\
\hline Hadlock1 & $14.00(9.37-30.00)$ & $<0.05$ & $-630.43(209.91)$ & -1041.84 to -219.01 \\
\hline Hadlock2 & $6.46(0.01-30.31)$ & $>0.05$ & $-233.41(340.04)$ & -899.89 to 433.06 \\
\hline Hadlock3 & $5.79(0.02-49.91)$ & - & $-237.79(366.68)$ & -956.48 to 480.91 \\
\hline Hadlock4 & $5.81(0.09-43.02)$ & $<0.05$ & $-293.74(344.90)$ & -969.74 to 382.26 \\
\hline Hadlock5 & $14.19(9.59-30.11)$ & $<0.05$ & $-637.32(209.59)$ & -1048.12 to -226.52 \\
\hline Shepard & $7.22(0.00-70.54)$ & $>0.05$ & $60.45(510.42)$ & -939.96 to 1060.87 \\
\hline Campbell & $10.70(0.38-25.84)$ & $<0.05$ & $-488.81(261.88)$ & -1002.09 to 24.47 \\
\hline Warsof1 & $13.99(3.36-37.09)$ & $<0.05$ & $-616.34(311.22)$ & -1226.34 to -6.34 \\
\hline Warsof2 & $5.80(0.08-29.33)$ & $>0.05$ & $-90.70(379.93)$ & -835.37 to 653.98 \\
\hline Combs & $9.69(0.15-29.25)$ & $<0.05$ & $-473.20(300.00)$ & -1061.20 to 114.81 \\
\hline Ott & $7.52(0.17-28.15)$ & $<0.05$ & $-365.07(311.49)$ & -975.59 to 245.45 \\
\hline
\end{tabular}

Group 4 includes 94 SGA babies with actual birth weight under 10 centile, median of weight is $2679 \mathrm{~g}$. The lowest MAPE has Combs (7.72\%). There is a significant difference between it and other equations ( $p<0.05$ ) except from Campbell formula (Tab. 6). Hadlock1, Hadlock5 and Ott formulas have the highest value of Spearman correlation. R equals 0.727 for each of them. Table 6 shows that all formulas have a tendency to overestimate predicting weight. The narrowest limits of agreement has Combs, while the widest range has Warsof 1.

Group 5 comprises 123 LGA babies with actual birth weight above 90 centile, median of weight is $4090 \mathrm{~g}$. The lowest MAPE has Warsof 2 (7.06\%). It differs significantly from the other equations ( $p<0.05$ ) except from Hadlock3, Hadlock2 and Shepard (Tab. 7). The strongest correlation values are for Ott $(R=0.537)$, Hadlock5 $(R=0.536)$, Hadlock1 $(R=0.532)$. All tested formulas have a tendency to underestimate actual birth weight, except for Shepard (Tab. 7).
Also Shepard formula has the widest limits of agreement. In contrast, the narrowest range is found for Campbell formula.

\section{DISCUSSION}

In our study we formed five groups, each of them should be analyzed separately.

For fetuses with ABW under $2500 \mathrm{~g}$, the most accurate formula is Hadlock3 (MAPE $=7.04 \%$ ). Hadlock3 has also the highest value of Spearman correlation $(R=0.845)$. According to other Hadlock formulas, all of them have high accuracy. It indicates that Hadlock formulas are stable. Esinler et al. [15] collated the performance of 18 different formulas for prediction of fetal weight. They compared formulas in the whole study population and subgroups by using percentage error (PE), absolute percentage error (APE) and Cronbach's alpha value. They reported that the lowest three mean APE values were associated with Hadlock4 (9.1\%), Hadlock1 (9.2\%) and Ott (9.8\%). Choi Wah Kong et al. [16] assesed the accuracy 


\begin{tabular}{|c|c|c|c|c|}
\hline $\begin{array}{l}\text { Regression formula } \\
10 \text { cent }\end{array}$ & Median APE [\%] (range) & $p$ value & mean $[g](S D)$ & $95 \%$ limits of agreement [g] \\
\hline Hadlock1 & $28.78(13.11$ - 164.33) & $<0.05$ & $828.13(279.56)$ & 280.20 to 1376.06 \\
\hline Hadlock2 & $11.12(0.15-57.83)$ & $<0.05$ & $284.29(340.19)$ & -382.47 to 951.06 \\
\hline Hadlock3 & $10.09(0.39-51.25)$ & $<0.05$ & $280.10(316.63)$ & -340.50 to 900.70 \\
\hline Hadlock4 & $8.75(0.38-50.41)$ & $<0.05$ & 238.94 (303.56) & -356.04 to 833.92 \\
\hline Hadlock5 & $28.49(12.88-163.95)$ & $<0.05$ & $820.72(279.74)$ & 272.42 to 1369.01 \\
\hline Shepard & $14.33(0.90-59.49)$ & $<0.05$ & $398.16(357.51)$ & -302.56 to 1098.88 \\
\hline Campbell & $9.26(0.06-48.27)$ & $>0.05$ & $227.81(299.26)$ & -358.75 to 814.37 \\
\hline Warsof1 & $22.61(0.07-74.04)$ & $<0.05$ & $525.55(395.80)$ & -250.21 to 1301.32 \\
\hline Warsof2 & $17.22(0.09-65.89)$ & $<0.05$ & $460.00(368.24)$ & -261.75 to 1181.74 \\
\hline Combs & $7.72(0.20-45.91)$ & - & $195.77(264.97)$ & -323.56 to 715.10 \\
\hline Ott & $9.16(0.54-51.25)$ & $<0.05$ & $237.07(284.83)$ & -321.19 to 795.34 \\
\hline
\end{tabular}

\begin{tabular}{|c|c|c|c|c|}
\hline $\begin{array}{l}\text { Regression formula } \\
90 \text { cent }\end{array}$ & Median APE [\%] (range) & $p$ value & mean [g] (SD) & $95 \%$ limits of agreement [g] \\
\hline Hadlock1 & $12.43(1.11-75.24)$ & $<0.05$ & $-485.49(374.14)$ & -1218.80 to 247.82 \\
\hline Hadlock2 & $7.16(0.01-30.31)$ & $>0.05$ & $-207.45(347.47)$ & -888.48 to 473.59 \\
\hline Hadlock3 & $7.13(0.02-49.91)$ & $>0.05$ & $-211.09(371.36)$ & -938.96 to 516.78 \\
\hline Hadlock4 & $7.58(0.09-43.02)$ & $<0.05$ & $-266.99(349.24)$ & -951.50 to 417.51 \\
\hline Hadlock5 & $12.59(1.11-75.24)$ & $<0.05$ & $-492.40(374.15)$ & -1225.74 to 240.93 \\
\hline Shepard & $7.26(0.03-70.54)$ & $>0.05$ & $77.32(501.22)$ & -905.06 to 1059.70 \\
\hline Campbell & $9.27(0.28-30.20)$ & $<0.05$ & $-414.08(289.73)$ & -981.96 to 153.80 \\
\hline Warsof1 & $12.77(0.12-37.09)$ & $<0.05$ & $-553.68(369.94)$ & -1278.76 to 171.41 \\
\hline Warsof2 & $7.06(0.08-29.33)$ & - & $-72.07(383.22)$ & -823.19 to 679.04 \\
\hline Combs & $10.33(0.22-29.25)$ & $<0.05$ & $-433.57(308.83)$ & -1038.88 to 171.74 \\
\hline Ott & $8.29(0.17-28.59)$ & $<0.05$ & $-332.56(316.72)$ & -953.33 to 288.22 \\
\hline
\end{tabular}

of INTERGROWTH-21 formula with the traditional Hadlock1 and Shepard formula. INTERGROWTH-21 had a higher mean of the APE (9.72\%) than Hadlock1 (6.93\%) or Shepard (8.96\%). According to newer technology, perhaps 3D methods might improve accuracy of estimation fetal weight [5]. Hasenoehrl et al. showed that the lowest mean absolute percentage error in birth weight estimation for fetuses under $2500 \mathrm{~g}$ belongs to 3D Schild formula (7.0\%) compared to Hadlock4 (8.0\%). The disadvantage of 3D ultrasonography is that it is time consuming method, it lasts longer, especially at the beginning of learning these technic.

Our analysis for fetuses between $2500 \mathrm{~g}$ and $4000 \mathrm{~g}$ shows that the most accurate formula is Ott (mean APE is $5.43 \%)$. Although, the highest Spearman correlations belong to Hadlock formulas. Hoopmann et al. [17] compared 35 formulae in 3416 fetuses with weight between $2500 \mathrm{~g}$ and $4000 \mathrm{~g}$. They determined and compared the mean percentage error, the mean absolute percentage error, also the proportions of estimates within the error ranges of 5 , 10,20 and $30 \%$. In addition, separate regression lines were calculated for the relationship between estimated and actual birth weight.. Halaska formula had the best value of mean absolute percentage error (6.6\%). 20 formulae (Halaska, Schild I, Shinozuka, Sabbagha, Hadlock III, Hadlock I, Ott, Hadlock V, Combs, Hadlock II, Merz I, Rose-McCallum, Shepard, Warsof, Ferrero, Hadlock VI, Campbell, Persson, Hansmann, Jordaan) exhibited MAPE values of $\leq 10 \%$. In our study, estimation of fetal weight with Campbell, Combs and Ott formulae have a tendency to underestimate fetal weight, other 8 formulae overestimate fetal weight. These results contrast with Hoopmann et al. study [17], where the majority of the tested formulae gave underestimations of the 
Table 8. R Spearman correlation for groups from 1 to 5

\begin{tabular}{|l|l|l|l|l|l|}
\hline \multirow{2}{*}{ Regression formula } & \multicolumn{2}{l}{ R Spearman correlation } & \multicolumn{3}{l}{} \\
\cline { 2 - 6 } & Group 1 & Group 2 & Group 3 & Group 4 & Group 5 \\
\hline Hadlock1 & 0.834 & 0.683 & 0.332 & 0.727 & 0.532 \\
\hline Hadlock2 & 0.820 & 0.661 & 0.312 & 0.709 & 0.527 \\
\hline Hadlock3 & 0.845 & 0.680 & 0.305 & 0.706 & 0.527 \\
\hline Hadlock4 & 0.841 & 0.686 & 0.319 & 0.719 & 0.531 \\
\hline Hadlock5 & 0.834 & 0.682 & 0.329 & 0.727 & 0.536 \\
\hline Shepard & 0.814 & 0.648 & $0.195^{*}$ & 0.659 & 0.464 \\
\hline Campbell & 0.775 & 0.630 & 0.229 & 0.691 & 0.483 \\
\hline Warsof1 & 0.674 & 0.375 & 0.218 & 0.563 & 0.354 \\
\hline Warsof2 & 0.742 & 0.640 & 0.305 & 0.659 & 0.527 \\
\hline Combs & 0.833 & 0.671 & 0.326 & 0.725 & 0.526 \\
\hline Ott & 0.838 & 0.676 & 0.328 & 0.727 & 0.537 \\
\hline
\end{tabular}

actual birth weight. Analysis of 3D formulas [5] shows higher accuracy of 3D Schild formula compared to Hadlock4 in group of fetuses between $2500 \mathrm{~g}$ and $3000 \mathrm{~g}$ (mean absolute percentage error $5.3 \%$ vs $7.8 \%$ ) and those between $3500 \mathrm{~g}$ and $4000 \mathrm{~g} \mathrm{(4.8 \%} \mathrm{vs} 9.6 \%)$.

Group 3 comprises fetuses with ABW over $4000 \mathrm{~g}$, the most accurate formula is Hadlock3 (MAPE $=5.79 \%$ ). The highest correlation value has: Hadlock $1(R=0.332)$. There is a visible relation (Tab. 8); the Spearman correlation, power of relationship, decreases with actual birth weight. According to factors affecting the accuracy of fetal weight, some older studies claim that maternal BMI [18] or fetal sex [19] are apparently not a significant influence on measurement error. Esinler et al. [15] showed that the lowest mean APE in these group were associated with Merz II (4.8\%), Hadlock3 (5.6\%), Hadlock4 (5.8\%) formulae. Hart et al. [20] developed formula, which includes AC, HC, FL and also maternal weight. They showed that new formula compared to seven formulas allows to estimate better weight in macrosomic fetuses. Mean APE for Hart formula was 3.69\%. Unfortunately, maternal weight during USG examination is not routinely asked, that is why we can not use these formula in our study. Also, appliance of 3D Schild formula could improve accuracy of estimation fetuses over $4000 \mathrm{~g}$ [5]. There is an evident problem with underestimation fetuses with $A B W$ over $4000 \mathrm{~g}$ in our and others study [21].

For SGA babies the most accurate formula is Combs (MAPE $=7.72 \%)$. Our study confirms that nontargeted formulas have a tendency to overestimate the weight of SGA fetuses. The drawback of our study is lack of specific targeted formulas for SGA fetuses. Melamed et al. [22] shows that the best performing model is targeted model of Scott et al [23]. Although, Hadlock formulae reaches one of the highest accuracies in these study. The accuracy of fetal weight estimation is different in specific subgroups of SGA fetuses: early versus late SGA, asymmetric versus symmetric, and presence of Doppler abnormalities. Usefulness of Hadlock formulae was shown by Shen et al. [24]. These study reveals high sensitivity and high specificity of Hadlock formulae.

The most accurate formula for LGA is Warsof2 (MAPE $=7.06 \%$ ), following formulae with the lowest MAPE are Hadlock3 (7.13\%) and Hadlock2 (7.16\%). The formula with the highest correlation between EFW and ABW is Ott $(R=0.537)$. Aviram et al. [25] shows that there is a wide variation in EFW formulas performance for detecting LGA. To the most accurate belong those, which contain abdominal circumference $(A C)$, femur length ( $F L)$ and biparietal diameter (BD). Hadlock formulae have the lowest Euclidean distance. Rosati et al [26] claims that similarly to our study, Warsof 2 formula is the most accurate (the lowest mean percentage error). These study shows the best ability to identify fetal macrosomia with formulas based only on abdominal measurement (Warsof2, Hadlock1, Campbell). There is a problem in understanding definitions of macrosomia [weight - (grams)] and large-for-gestational age (centile) in many studies.

\section{CONCLUSIONS}

Our study shows that various formulas have an impact of accuracy of estimated fetal weight in different weight ranges. Especially, when SGA or LGA is suspected. It is important to use different formulas, because it predicts better actual birth weight and helps in clinical decisions. In everyday clinical practice, median of absolute percentage error (MAPE) seems to be the easiest and the most useful parameter. To conclude, the most accurate formula for fetuses under $2500 \mathrm{~g}$ is Hadlock3, for fetuses between $2500 \mathrm{~g}$ and $4000 \mathrm{~g}$ is Ott, for fetuses above $4000 \mathrm{~g}$ is Hadlock3, for suspected SGA babies is Combs and for suspected LGA babies is Warsof2. In future, we could extend our work and 
analyze fetal 3D ultrasonography. Every year, new formulae and technologies are introduced, however we can rely on accuracy of those we have known and used for years [27].

\section{REFERENCES:}

1. Boulet $\mathrm{SL}$, Alexander GR, Salihu HM, et al. Macrosomic births in the united states: determinants, outcomes, and proposed grades of risk. Am J Obstet Gynecol. 2003; 188(5): 1372-1378, doi: 10.1067/mob.2003.302, indexed in Pubmed: 12748514.

2. Ju H, Chadha Y, Donovan T, et al. Fetal macrosomia and pregnancy outcomes. Aust N Z J Obstet Gynaecol. 2009; 49(5): 504-509, doi: 10.1111/j. 1479-828X.2009.01052.x, indexed in Pubmed: 19780734.

3. Beune IM, Bloomfield FH, Ganzevoort W, et al. Consensus Based Definition of Growth Restriction in the Newborn. J Pediatr. 2018; 196: 71-76. e1, doi: 10.1016/j.jpeds.2017.12.059, indexed in Pubmed: 29499988.

4. Liu J, Wang XF, Wang $Y$, et al. The incidence rate, high-risk factors, and short- and long-term adverse outcomes of fetal growth restriction: a report from Mainland China. Medicine (Baltimore). 2014; 93(27): e210, doi: 10.1097/MD.0000000000000210, indexed in Pubmed: 25501078.

5. Schild RL, Fimmers R, Hansmann M. Fetal weight estimation by three-dimensional ultrasound. Ultrasound Obstet Gynecol. 2000; 16(5): 445-452, doi: 10.1046/j.1469-0705.2000.00249.x, indexed in Pubmed: 11169329.

6. Hadlock FP, Harrist RB, Sharman RS, et al. Estimation of fetal weight with the use of head, body, and femur measurements--a prospective study. Am J Obstet Gynecol. 1985; 151(3): 333-337, doi: 10.1016/00029378(85)90298-4, indexed in Pubmed: 3881966.

7. Kumara D, Perera H. Evaluation of six commonly used formulae for sonographic estimation of fetal weight in a Sri Lankan population. Sri Lanka Journal of Obstetrics and Gynaecology. 2010; 31(1): 20, doi: 10.4038/sljog.v31i1.1735.

8. Charles UE, Kester IE, Kennedy KA, et al. Validity of common ultrasound methods of fetal weight estimation in late pregnancy among women in Kwale, Niger Delta region, Nigeria.

9. Shepard MJ, Richards VA, Berkowitz RL, et al. An evaluation of two equations for predicting fetal weight by ultrasound. Am J Obstet Gynecol. 1982; 142(1): 47-54, doi: 10.1016/s0002-9378(16)32283-9, indexed in Pubmed: 7055171.

10. Campbell S, Wilkin D. Ultrasonic measurement of fetal abdomen circumference in the estimation of fetal weight. Br J Obstet Gynaecol. 1975; 82(9): 689-697, doi: 10.1111/j.1471-0528.1975.tb00708.x, indexed in Pubmed: 1101942.

11. Warsof SL, Wolf P, Coulehan J, et al. Comparison of fetal weight estimation formulas with and without head measurements. Obstet Gynecol. 1986; 67(4): 569-573, indexed in Pubmed: 3515257.

12. Combs CA, Jaekle RK, Rosenn B, et al. Sonographic estimation of fetal weight based on a model of fetal volume. Obstet Gynecol. 1993; 82(3): 365-370, indexed in Pubmed: 8355935.

13. OttWJ, Doyle S, Flamm S, et al. Accurate ultrasonic estimation of fetal weight. Prospective analysis of new ultrasonic formulas. Am J Perinatol. 1986; 3(4): 307-310, doi: 10.1055/s-2007-999885, indexed in Pubmed: 3530267.
14. Bland JM, Altman D. tatistical methods for assessing agreement between two methods of clinical measurement. The Lancet. 1986; 327(8476): 307-310, doi: 10.1016/s0140-6736(86)90837-8.

15. Esinler D, Bircan O, Esin S, et al. Finding the best formula to predict the fetal weight: comparison of 18 formulas. Gynecol Obstet Invest. 2015; 80(2): 78-84, doi: 10.1159/000365814, indexed in Pubmed: 26183256.

16. Kong CW, To WW. Comparison of the accuracy of INTERGROWTH-21 formula with other ultrasound formulae in fetal weight estimation. Taiwan J Obstet Gynecol. 2019; 58(2): 273-277, doi: 10.1016/j. tjog.2019.01.019, indexed in Pubmed: 30910152.

17. Hoopmann M, Kagan KO, Sauter A, et al. Comparison of Errors of 35 Weight Estimation Formulae in a Standard Collective. Geburtshilfe Frauenheilkd. 2016; 76(11): 1172-1179, doi: 10.1055/s-0042-118598, indexed in Pubmed: 27904167.

18. Farrell $T$, Holmes $R$, Stone $P$. The effect of body mass index on three methods of fetal weight estimation. BJOG. 2002; 109(6): 651-657, doi: 10.1111/j.1471-0528.2002.01249.x, indexed in Pubmed: 12118643.

19. Ott WJ, Doyle $S$, Flamm S, et al. Accurate ultrasonic estimation of fetal weight. Am J Perinatol. 1985; 2(3): 178-182, doi: 10.1055/s-2007-999944, indexed in Pubmed: 3893450.

20. Hart NC, Siemer J, Meurer B, et al. Macrosomia - a new formula for optimized fetal weight estimation. Geburtshilfe und Frauenheilkunde. 2008; 68(S 01), doi: 10.1055/s-0028-1089271.

21. Faschingbauer $F$, Voigt $F$, Goecke TW, et al. Fetal weight estimation in extreme macrosomia ( $\geq 4,500 \mathrm{~g}$ ): comparison of 10 formulas. Ultraschal Med. 2012; 33(7): E62-E67, doi: 10.1055/s-0031-1281833, indexed in Pubmed: 22179801

22. Melamed N, Ryan G, Windrim R, et al. Choice of Formula and Accuracy of Fetal Weight Estimation in Small-for-Gestational-Age Fetuses.JUltrasound Med. 2016;35(1):71-82, doi: 10.7863/ultra.15.02058, indexed in Pubmed: 26635253.

23. Scott F, Beeby $P, A b b o t t ~ J$, et al. New formula for estimating fetal weight below $1000 \mathrm{~g}$ : comparison with existing formulas. J Ultrasound Med. 1996; 15(10): 669-672, doi: 10.7863/jum.1996.15.10.669, indexed in Pubmed: 8887237.

24. Shen Y, Zhao W, Lin J, et al. Accuracy of sonographic fetal weight estimation prior to delivery in a Chinese han population. J Clin Ultrasound. 2017; 45(8): 465-471, doi: 10.1002/jcu.22463, indexed in Pubmed: 28332212

25. Aviram A, Yogev $Y$, Ashwal E, et al. Prediction of large for gestational age by various sonographic fetal weight estimation formulas-which should we use? J Perinatol. 2017; 37(5): 513-517, doi: 10.1038/jp.2017.5, indexed in Pubmed: 28151496.

26. Rosati $P$, Arduini M, Giri $C$, et al. Ultrasonographic weight estimation in large for gestational age fetuses: a comparison of 17 sonographic formulas and four models algorithms. J Matern Fetal Neonatal Med. 2010; 23(7): 675-680, doi: 10.3109/14767050903410631, indexed in Pubmed: 19895358.

27. Hammami A, Mazer Zumaeta A, Syngelaki A, et al. Ultrasonographic estimation of fetal weight: development of new model and assessment of performance of previous models. Ultrasound Obstet Gynecol. 2018; 52(1): 35-43, doi: 10.1002/uog.19066, indexed in Pubmed: 29611251. 